\title{
Penyelesaian Permasalahan Menggunakan Konsep SMART CITY di Kota Bandung
}

\section{Problems Solving with Using The Smart City Concept in the City of Bandung}

\author{
Syahrul Ramadhan ${ }^{\mathrm{a}^{*}}$ \\ ${ }^{a}$ Institut Teknologi Bandung, Bandung, Indonesia
}

\begin{abstract}
Abstrak
Penerapan smart city oleh kota-kota di Indonesia masih terbilang sedikit karena konsep smart city ini terbilang hal yang baru populer di Indonesia, atau mungkin juga karena belum banyak percontohan yang bisa dijadikan ucuan oleh kota-kota lain di Indonesia. Tulisan ini menjelaskan mengenai smart city, permasalahan perkotaan di Indonesia dan penerapan konsep smart city di Bandung untuk menyelesaikan permasalahan perkotaan di Kota Bandung. Metode penelitian yang digunakan adalah studi literatur. Kota Bandung merupakan salah satu kota yang berhasil menerapkan konsep smart city, terlebih lagi pada bidang ruang terbuka hijau (taman), transportasi dan pelayanan publik.
\end{abstract}

Kata kunci: Kota Bandung, Pelayanan Publik, RTH, Smart City, Transportasi

\begin{abstract}
The smart city application in cities of Indonesia is still a little bit because the concept of smart city is fairly new in Indonesia, or maybe because there are not many examples that can be emulated by other cities in Indonesia. This paper explains about smart city, urban problems in Indonesia and the application of the smart city concept in Bandung to solve urban problems in the city of Bandung. The research method used is a literature study. Bandung city is one of the cities that has successfully implemented the smart city concept, especially in the fields of green open space (parks) in transportation and public services.
\end{abstract}

Keyword: Bandung City, Public Service, Green Open Space, Smart City, Transportation

\section{Pendahuluan}

Akhir -akhir ini sering terdengar kata smart city atau dalam Bahasa Indonesia berarti "kota cerdas". Namun, masih banyak orang yang belum mengetahui pasti apa itu smart city dan apa manfaat serta kelebihan dari smart city ini. Saat ini telah banyak kota-kota di dunia yang menerapkan konsep smart city, tetapi penerapan smart city di kota - kota Indonesia masih terbilang sedikit karena konsep smart city merupakan konsep baru yang populer di Indonesia, atau mungkin juga karena belum banyak contoh di Indonesia yang bisa diikuti oleh kota-kota lain. Salah satu kota di Indonesia yang menerapkan konsep smart city adalah Kota Bandung. Kota Bandung sudah menerapkan konsep smart city semenjak kepemimpinan Bapak Walikota Ridwan Kamil..

Rumusan masalah yang akan dijawab pada esai ini adalah:

- Apa definisi dari smart city?

- Apa saja indikator smart city dan Indikator yang diterapkan di Kota Bandung?

\footnotetext{
${ }^{*}$ Corresponding author. Syahrul Ramadhan.

E-mail address: arulura45@gmail.com.
} 
- Apa saja permasalahan umum yang terjadi di perkotaan (Ruang Terbuka Hijau (Taman), Transportasi, dan Pelayanan Publik)?

- Bagaimana konsep dan penerapan smart city di Kota Bandung?

Kota Bandung merupakan salah satu kota yang berhasil menerapkan konsep smart city terlebih lagi pada bidang RTH (Ruang Terbuka Hijau), transportasi, dan pelayanan publik.

\section{Metode}

Sebagai proses terpenuhinya data dan informasi yang diperlukan pada penulisan ini, maka metodologi yang digunakan adalah deskriptif-kualitatif dengan teknik pengumpulan data berupa studi literatur. Studi literatur adalah cara untuk mengumpulkan data-data atau referensi teori yang berhubungan dengan topik yang diangkat. Referensi tersebut berisikan tentang konsep smart city yang telah diterapkan di Kota Bandung untuk menyelesaikan berbagai macam masalah yang ada dengan memanfaatkan segala sumber daya yang ada di Kota Bandung

\section{Hasil dan Pembahasan}

"Menurut Giffinger (2010 dalam (Lee, 2014)), smart city merupakan kota dengan investasi modal manusia dan sosial, dengan transportasi (tradisional) dan infrastruktur komunikasi modern serta pembangunan ekonomi yang berkelanjutan dan kualitas hidup yang tinggi, dengan manajemen SDA yang bijaksana melalui tata pemerintahan yang partisipatif "(Hasibuan \& Sulaiman, 2019). "Menurut Caragliu dan Nijkamp (2009) menyatakan bahwa smart city adalah kota yang mampu menggunakan sumber daya manusia (SDM), modal sosial, dan infrastruktur telekomunikasi moren untuk mewujudkan pertumbuhan ekonomi berkelanjutan dan kualitas kehidupan yang tinggi, dengan manajemen sumber daya yang bijaksana melalui pemerintahan berbasis partisipasi masyarkat." (Muliarto, 2015). Dari kedua definisi diatas disimpulkan bahwa pengertian smart city adalah konsep penataan kota yang berkelanjutan dari berbagai aspek sehingga dapat menjawab permasalahan saat ini dan di masa depan.

Berdasarkan pengertian yang telah dipaparkan diatas, smart city ini memanfaatkan segala sumber daya yang ada agar sebuah kota dapat menyelesaikan masalah di masa kini dan masa depan. "Sebuah kota diklarifikasikan menjadi smart city apabila sudah memenuhi 6 indikator, yaitu: smart economy, smart government, smart environment, smart people, smart monility, dan smart living" (The Government Summit, 2015). "Bandung sudah menjalankan kurang lebih 10 indikator, yaitu: smart government, smart education, smart transportation, health smart, smart energy, smart surveillance, smart environment, smart society, smart payment and smart commerce" (sustainabledevelopment.un.org). Ini menunjukkan bahwa Bandung sudah memenuhi indikator smart city.

Penerapan smart city tidak terlepas dari pemanfaatan Teknologi, Informasi, dan Komunikasi (TIK). Kota Bandung pastinya memanfaatkan TIK dalam penerapan konsep smart city, bahkan Walikota Bandung membuat Bandung Command Center. "Bandung Comand Center, memasok data dari dinas, badan Pemerintahan Kota Bandung, serta menghubungkan dan memantau kondisi jalanan kota lewat kamera pengawas" (SM, 2015). "Dalam Command Center tersebut banyak terdapat aplikasi yang bisa memonitor keadaan Bandung. didalamnya ada data cuaca, peta, video feed, special vehicles location, video analisis dan sebagainya." (Ahmad, 2015). Pemerintah Bandung juga memasang banyak CCTV di ruas jalan yang ada di Kota Bandung sebagai pendukung data.

Sebuah kota terasa kurang lengkap dan kurang indah apabila ruang terbuka hijau dan taman masih sedikit jumlahnya. "Salah satu fungsi dari RTH perkotaan (urban forest) pada aspek ekologis yang saat ini banyak dibahas oleh berbagai kalangan terkait dengan perannya baik dalam konteks penurunan emisi gas rumah kaca (GRK) maupun penetralisir polusi udara perkotaan, terutama karbon dioksida (CO2) adalah fungsinya sebagai reservoir karbon" (Administrator_bplh, 2014). Ruang terbuka hijau (taman) juga merupakan tempat untuk komunitas komunitas yang ada di kota berkumpul dan melakukan berbagai hal. Apabila ruang terbuka hijau (taman) di suatu kota masih sedikit, maka permasalahan, seperti banjir, peningkatan suhu, kawasan yang rendah nilai jual, tidak ada tempat bermain, dan lain lain akan bermunculan seiring berjalannya waktu. 
Permasalahan kurangnya ruang terbuka hijau (taman) ini sudah banyak berkurang di Kota Bandung karena Bapak Ridwan Kamil sebagai Walikota Bandung sudah membuka dan membangun banyak ruang terbuka hijau dan innovative space, seperti Taman Jomblo, Taman Fotografi, Taman Skateboard, Taman Persib, Taman Film, Alun Alun Kota Bandung, dan lain lain (Gambar 1). Walikota Bandung juga telah menyebar 10.000 titik akses WiFi di Kota Bandung dan tiap taman pun terdapat akses WiFi agar semua warganya mudah mengakses internet. Pemerintah Kota Bandung juga telah membuat rencana RTH, seperti yang terlihan pada Tabel 1. Pembangunan taman taman ini merupakan salah satu penerapan konsep smart city karena dapat memenuhi indikator smart people dan smart environment.

Tabel 1. RTH Eksisting dan RTH Kota Bandung Berdasarkan RTRW Kota Bandung 2011-2031 (Master Plan Ruang Terbuka Hijau Kota Bandung 2011-2031 (Pemkota Bandung 2012)

\begin{tabular}{ccccc}
\hline \multirow{2}{*}{ Jenis RTH } & \multicolumn{2}{c}{ Eksisting } & \multicolumn{2}{c}{ Rencana } \\
\cline { 2 - 5 } & Luas (Ha) & \% & Luas (Ha) & \% \\
\hline Sempadan Sungai & 18.31 & 0.11 & 18.31 & 0.11 \\
\hline Sempadan rel kereta & 6.42 & 0.004 & 9.63 & 0.06 \\
\hline Sempadan SUTT & 10.17 & 0.07 & 10.17 & 0.07 \\
\hline Sempadan jalan & 176.91 & 1.06 & 264.34 & 1.58 \\
\hline Taman Kota & 218.07 & 1.3 & 2713.9 & 15.92 \\
\hline TPU & 148.14 & 0.89 & 292 & 1.74 \\
\hline Kawasan Konservasi & 1.12 & 0.02 & 4.12 & 0.02 \\
\hline lain-lain & 43604 & 2.61 & 92.58 & 0.55 \\
\hline RTH PUBLIK & 1018.54 & 6.1 & 3404.05 & 20 \\
\hline Perumahan & 55.6 & 0.33 & 1090 & 6.36 \\
\hline Hankam & 114.01 & 0.68 & 60.84 & 0.36 \\
\hline Pendidikan,perdagangan & 722.34 & 4.32 & 549.25 & 3.28 \\
\hline RTH PRIVAT & 891.95 & 5.33 & 1700.09 & 10 \\
\hline RTH Kota Bandung & 1910.49 & 11.43 & 5140.14 & 30 \\
\hline
\end{tabular}

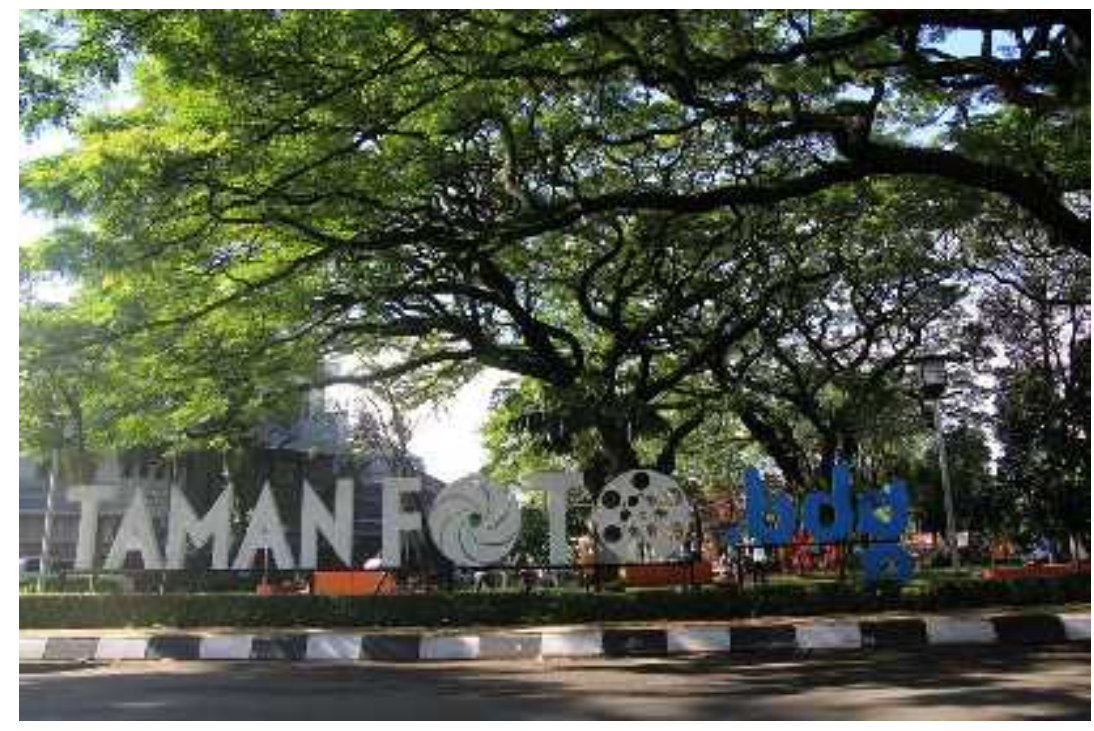

Gambar 1 Taman Foto Bandung (www.disparbud.jabarprov.go.id, 2015)

Permasalahan selanjutnya adalah masalah transportasi. Masalah transportasi pada umumnya adalah kemacetan, emisi, karbon, dan mobilitas yang tidak efisien. Kemacetan terjadi karena disebabkan tidak seimbangnya jumlah kendaraan dibandingkan ruas jalan, kurangnya transportasi massal, pelanggaran lalu lintas, kecelakaan, kerusakan jalan, dan lain lain. Emisi karbon suatu kota akan bertambah jumlahnya seiring dengan bertambahnya jumlah kendaraan. Emisi karbon dapat menyebabkan permasalahan, seperti pemanasan global, penyakit, dan lain lain. Mobilitas yang tidak efisien dapat menyebabkan perekonomian suatu kota terganggu dan 
tidak berjalan lancar. Kota Bandung juga mengalami permasalahan, seperti itu, padahal sebuah transportasi membuat mobilitas semua orang dapat melakukan aktifitas dengan cepat dan akan berpengaruh terhadap perputaran uang juga.

Masalah transportasi di Kota Bandung sebentar lagi akan berkurang karena Kota Bandung sekarang ini sedang menjalankan proyek pembangunan bidang transportasi, seperti pembangunan LRT, Skybridge, Bus Trans Metro Bandung, Bike Sharing Bandung (Gambar 2). Proyek-proyek tersebut merupakan upaya yang dilakukan oleh Walikota Bandung untuk mengurangi emisi karbon dan mengurangi penggunaan BBM di Kota Bandung. Efek dari pengurangan emisi karbon adalah suhu kota yang lebih dingin, penyebab penyakit berkurang, dan lain-lain. Selain proyek pembangunan tersebut, Walikota Bandung juga membuat smart parking system yang diharapkan dapat memudahkan akses keluar dan masuk parkir yang benar dan juga dapat mengurangi penggunaan tiket parkir kertas yang sangat tidak ramah lingkungan. Walikota Bandung juga membuat program mingguan, yaitu pada hari senin dan kamis, anakanak sekolah dapat menaiki bus gratis untuk menuju sekolah dan pada hari jumat ditetapkan sebagai hari jumat bersepeda. Program tersebut merupakan penerapan smart city karena memenuhi indikator smart transportation dan smart energy.

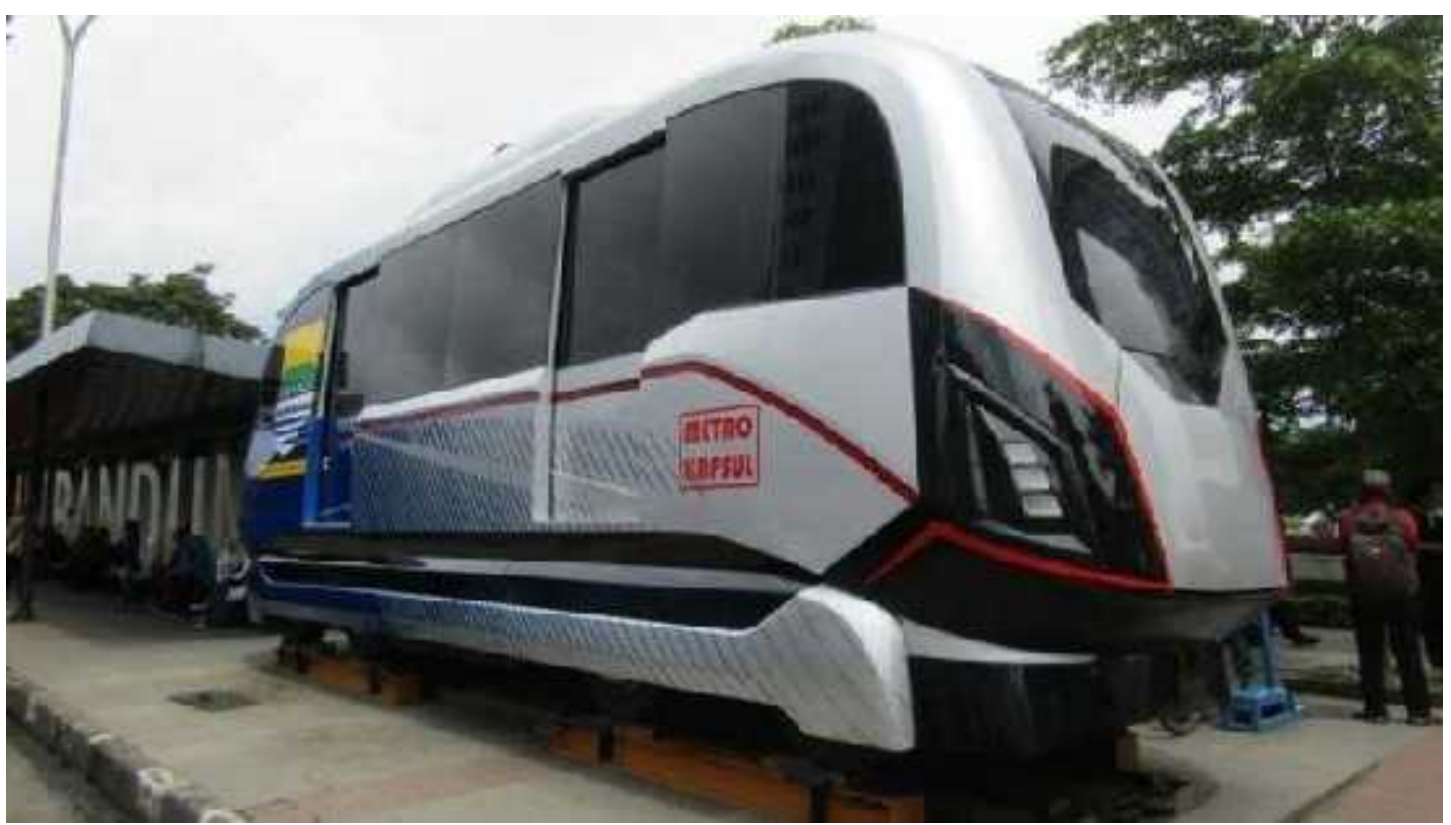

Gambar 2 Metro Kapsul (LRT) Bandung (www.bbc.com, 2017)

Permasalahan selanjutnya adalah masalah pelayanan publik. Banyak yang mengeluh tentang pelayanan publik yang kurang maksimal, contohnya, seperti lambatnya respon, susah, dan bingung untuk melakukan pengaduan, proses pembuatan surat dan ijin yang lama, dan masih banyak lagi masalah-masalah yang ada. "Tidak cukup biasa saja dalam melakukan pelayanan publik. Intinya adalah pelayanan publik sekarang jelek. Kami ingin yang jelek-jelek ini dilombakan. Yang kita ingin lakukan perbaikan dan peningkatan kualitas pelayanan publik. Kita keluarkan program dan kompetisi. Kita ingin yang jelek-jelek ini diperbaiki. Ikut kompetisi, diperbaiki" kata Deputi Bidang Pelayanan Publik Kementrian Pendayagunaan Aparatur Negara dan Reformasi Birokrasi Mirawati Sudjono (Medistira, 2015). Apabila masalah ini terus dibiarkan, maka rasa kepercayaan masyarakat terhadap petinggi-petingginya akan berkurang, lalu apabila urusan membuat ijin dan membuat surat masih memakan waktu lama akan menimbulkan banyak tindak criminal, seperti suap, calo, joki, dan lain-lain.

Namun, di Kota Bandung masalah pelayanan publik sudah jarang ditemui karena Kota Bandung telah menerapkan konsep smart government. Walikota bandung mewajibkan seluruh instansi, camat ataupun kelurahan agar mempunyai akun media sosial, seperti twitter dan facebook, agar proses pengaduan masalah mudah dilakukan. Juga terdapat aplikasi bernama Bandung Smart City, pada aplikasi ini disediakan tempat bagi para warganya yang ingin memberikan laporan maupun keluhan kepada Pemerintah Kota Bandung, gambaran aplikasinya terlihat pada Gambar 3. Selain penggunaan aplikasi, Kota Bandung juga bekerja sama dengan 
TMC Polda, Damkar, Dishub, dan Satpol PP. Kerja sama ini bertujuan agar seluruh proses pengaduan cepat ditanggapi dan ditindak, bahkan warga pun dapat menilai kinerja pelayanan publik di kecamatan maupun di kelurahan Kota Bandung dengan mengakses SIP Bdg Juara (Sistem Informasi Penilaian Bandung) (Gambar 4) melalui internet dan web/ situs ini bisa diakses oleh semua orang dengan mudah. Masih banyak lagi aplikasi yang tersedia, seperti civil regristation online, panic button, sistem informasi pelayanan $\mathrm{PBB}$, dan lain-lain. Dapat dilihat bahwa pemanfaatan teknologi dalam pelayanan publik di Kota Bandung sangat maksimal sehingga masyarakat Kota Bandung menjadi pribadi yang cerdas dan sadar teknologi (smart people).

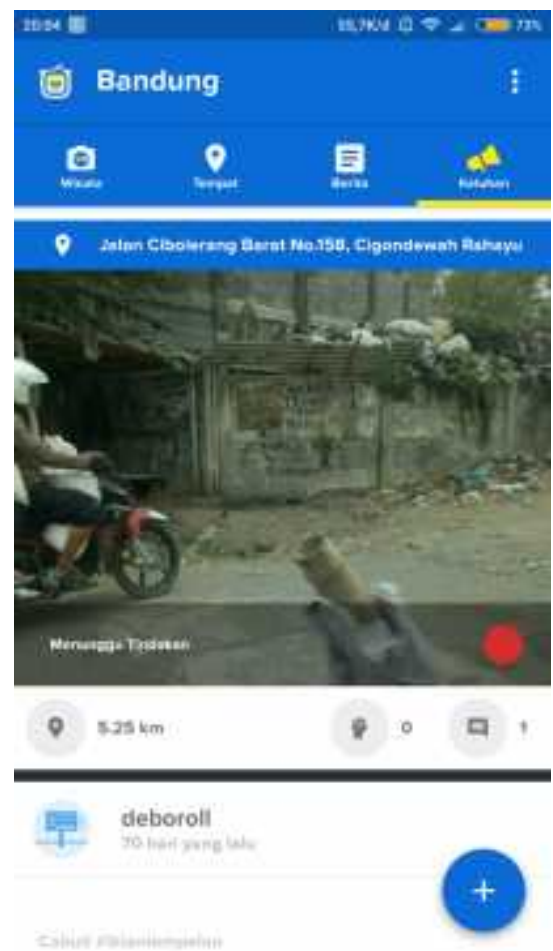

Gambar 3 Screenshot Aplikasi Bandung Smart City (Dokumentasi Pribadi, 2017)

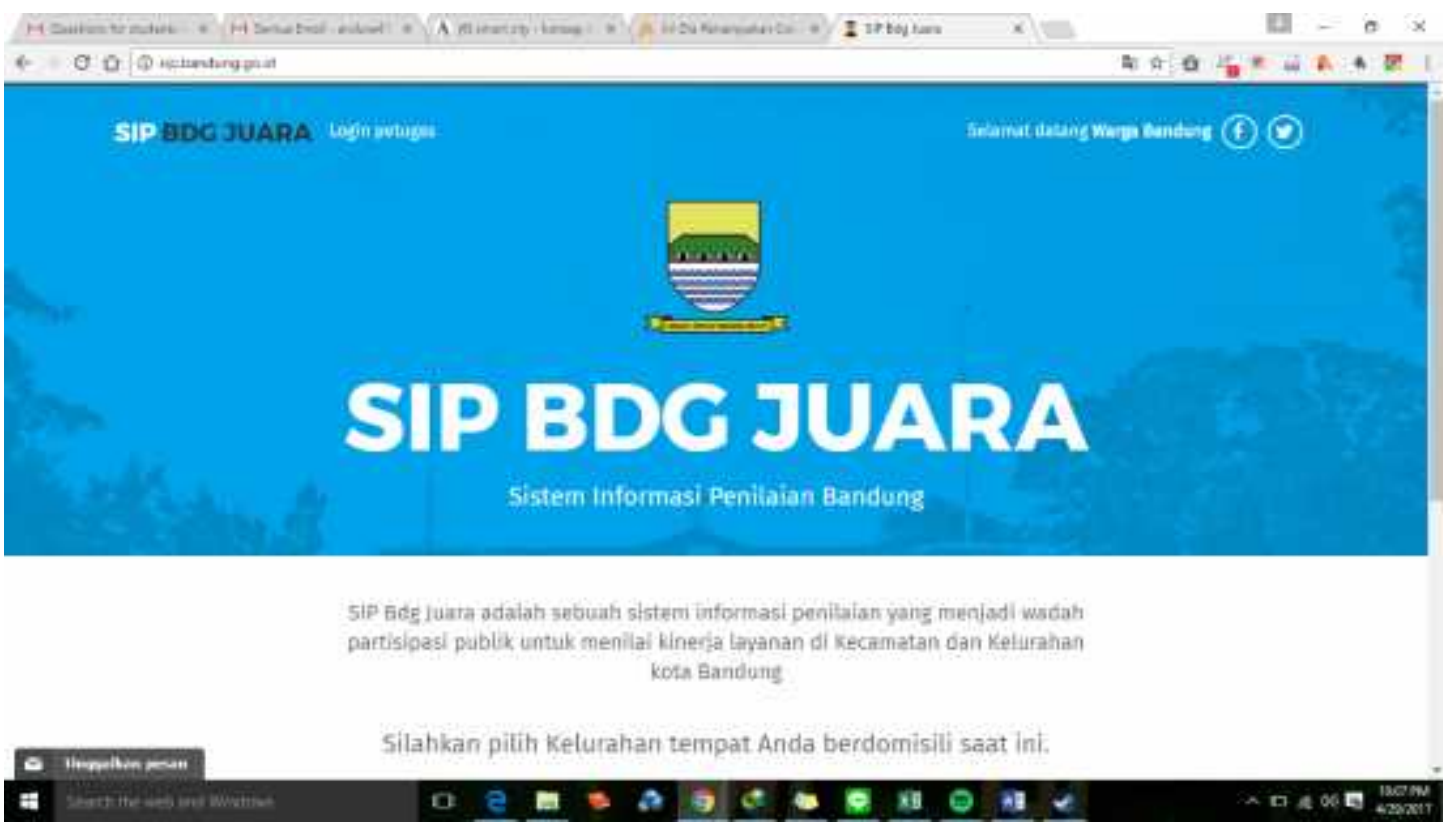

Gambar 4 Screenshot website SIP BDG JUARA (Dokumentasi Pribadi, 2017). 


\section{Kesimpulan}

Dapat disimpulkan bahwa konsep smart city ini memanfaatkan sumber daya yang ada untuk membuat kota menjadi sustainable dan menjawab permasalahan secara efektif dan efisien. Kota Bandung juga memenuhi indikator smart city. Permasalahan ruang terbuka hijau (taman), transportasi, dan pelayanan publik pun banyak terselesaikan dengan menerapkan konsep smart city. konsep smart city juga membuat masyarakat sadar, kritis, dan peduli terhadap permasalahan yang ada di sekitar mereka. Penerapan smart city ini juga membuat seluruh masyarakat dan instansi di Kota Bandung saling bekerja sama dalam menyelesaikan permasalahan.

Diharapkan konsep smart city ini dapat diterapkan juga pada bidang pariwisata di Kota Bandung, seperti perpustakaan umum, museum, wisata alam, kebun binatang, dan lain-lain. Lalu, diharapkan dapat mengurangi atau merelokasi PKL yang berjualan di bahu jalan Kota Bandung dengan menggunakan dan memanfaatkan konsep smart city atau memanfaatkan teknologi internet dan online shop, seperti Go-Food untuk memberdayakan pedagang pedagang kecil. Semoga semua program dan fasilitas yang ada tidak hanya berlangsung sementara, tetapi dapat dirawat dan terus dikontrol secara rutin kelayakan fasilitas dan aplikasi yang ada. Keberhasilan Kota Bandung dalam menerapkan konsep smart city ini agar dapat disebarkan ke kota-kota lain sebagai contoh.

\section{Referensi}

Administrator_bplh. (2014). Laporan Final Ruang Terbuka Hijau.

Ahmad, T. (2015). Bandung Command Center : Ruang Kontrol Ala Film Star Trek. Diambil 29 April 2017, dari infobdg.com website: http://www.infobdg.com/v2/bandung-command-center-ruangkontrol-ala-film-star-trek/.

Hasibuan, A., \& Sulaiman, O. K. (2019). Smart City, Konsep Kota Cerdas Sebagai Alternatif Penyelesaian Masalah Perkotaan Kabupaten/Kota, di Kota-Kota Besar Provinsi Sumatera Utara. Buletin Utama Teknik, 14(2), 127-135.

Kamil, R. (n.d.-a). Innovating Bandung. Diambil 29 April 2017, dari web.kominfo.go.id website: https://web.kominfo.go.id/sites/default/files/users/12/Expose Walikota Bandung (Innovation).pdf.

Kamil, R. (n.d.-b). Smart City bdg. Diambil 20 Februari 2017, dari Sustainabledevelopment.un.org website: https://sustainabledevelopment.un.org/content/documents/12659kamil.pdf.

Lee, J. (2014). A STUDY ON THE DEFINITION OF SMART CITY. 1-11.

Medistira, Y. (2015). Pelayanan Publik di Indonesia Masih Jelek! Diambil 29 April 2017, dari detiknews website: https://news.detik.com/berita/3097845/pelayanan-publik-di-indonesia-masih-jelek

Muliarto, H. (2015). Konsep Smart City; Smart Mobility. Bandung.

SM, T. (2015). Emil Jelaskan Sosal Manfaat dan Kinerja BCC kepada Dubes Rusia. Diambil 30 April 2017, dari Tribun Jabar website: http://jabar.tribunnews.com/2015/03/27/emil-jelaskan-soalmanfaat-dan-kinerja-bcc-kepada-dubes-rusia

The Government Summit. (2015). Smart Cities : Regional Perspectives. 